\title{
PERACARIDAS (CRUSTÁCEOS) DO ENTREMARES E INFRALITORAL RASO DE UMA PRAIA ARENOSA DO URUGUAI
}

\author{
Ramos, T. ${ }^{1}$ \& Defeo, O. ${ }^{1}$ \\ ${ }^{1}$ Universidad de la República (UDELAR), Facultad de Ciencias, Unidad de Ciencias del Mar (UNDECIMAR). \\ *Autor correspondente: taiara.ramos@gmail.com
}

Em ecologia de Praia arenosa no Uruguai existem poucos antecedentes relacionados com estudos ecológicos sobre a assembléia da ordem Peracarida, em particular nas zonas inferiores do médiolitoral, assim como no infralitoral raso. Sendo os peracaridos um dos componentes com maior diversidade e abundancia deste ecossistema. Em consequência, o objetivo principal deste trabalho foi realizar um estudo ecológico da fauna de peracaridas no entremarés e infralitoral raso da praia Barra Del Chuy, assim como sua relação com as características do ambiente. Também, avaliar tendências verão-inverno dos descritores biológicos amostrados.

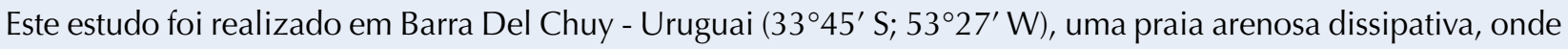
foram feitas duas coletas, uma no verão e outra no inverno de 2015. Foram realizadas amostras quantitativas por um corer, que incluíram os níveis superior e inferior do médiolitoral e o infralitoral raso a $0.25 \mathrm{~m}$ e $0.50 \mathrm{~m}$ de profundidade. Como consequências dessas amostras foram coletados 6156 exemplares de Peracarida, onde a densidade, abundancia, biomassa e riqueza de espécies apresentaram maiores valores no inverno. As análises de ordenação baseadas na composição das espécies mostram grupos definidos marcando diferenças entre o verão e o inverno assim como do entremarés com o infralitoral raso. No verão e inverno a biomassa, abundancia, densidade e riqueza de espécies apresentaram máximos valores no superior do médiolitoral diminuindo em direção ao nível superior do infralitoral. O tamanho corporal demonstra uma tendência contraposta entre o verão e o inverno. Todos os descritores ecológicos, com exceção da riqueza de espécies, tiveram uma tendência a diminuir com o aumento da porcentagem de matéria orgânica e do tamanho do grão de sedimento. Os resultados, apresentados neste trabalho aportam valiosa informação e esclarecimento sobre padrões bióticos e abióticos do espaço-temporal de um componente faunístico subestimado pela literatura cientifica relacionado com a ecologia de praias arenosas.

Palavras-chave: ecologia de praia, médio litoral, infralitoral raso. 